\title{
Correction to: HSP60 critically regulates endogenous IL-1 $\beta$ production in activated microglia by stimulating NLRP3 inflammasome pathway
}

Shalini Swaroop ${ }^{1}$, Anita Mahadevan², Susarla Krishna Shankar², Yogita K. Adlakha ${ }^{1 *}$ and Anirban Basu ${ }^{1 *}$

\section{Correction}

Upon publication of the original article [1], it was noticed that there is an error in Fig. 10, the dialog box in panel (b) was missing. The correct Fig. 10 is shown below.

\section{Author details}

${ }^{1}$ National Brain Research Centre, Manesar, Haryana 122052, India.

${ }^{2}$ Department of Neuropathology, National Institute of Mental Health and

Neurosciences, Bangalore, India.

Received: 30 October 2018 Accepted: 30 October 2018

Published online: 15 November 2018

\section{Reference}

1. Swaroop S, Mahadevan A, Shankar SK, Adlakha YK, Basu A. HSP60 critically

regulates endogenous IL-1 $\beta$ production in activated microglia by

stimulating NLRP3 inflammasome pathway. J Neuroinflammation. 2018 Dec;

15(1):177.

* Correspondence: yogita@nbrc.ac.in; anirban@nbrc.ac.in

${ }^{1}$ National Brain Research Centre, Manesar, Haryana 122052, India 


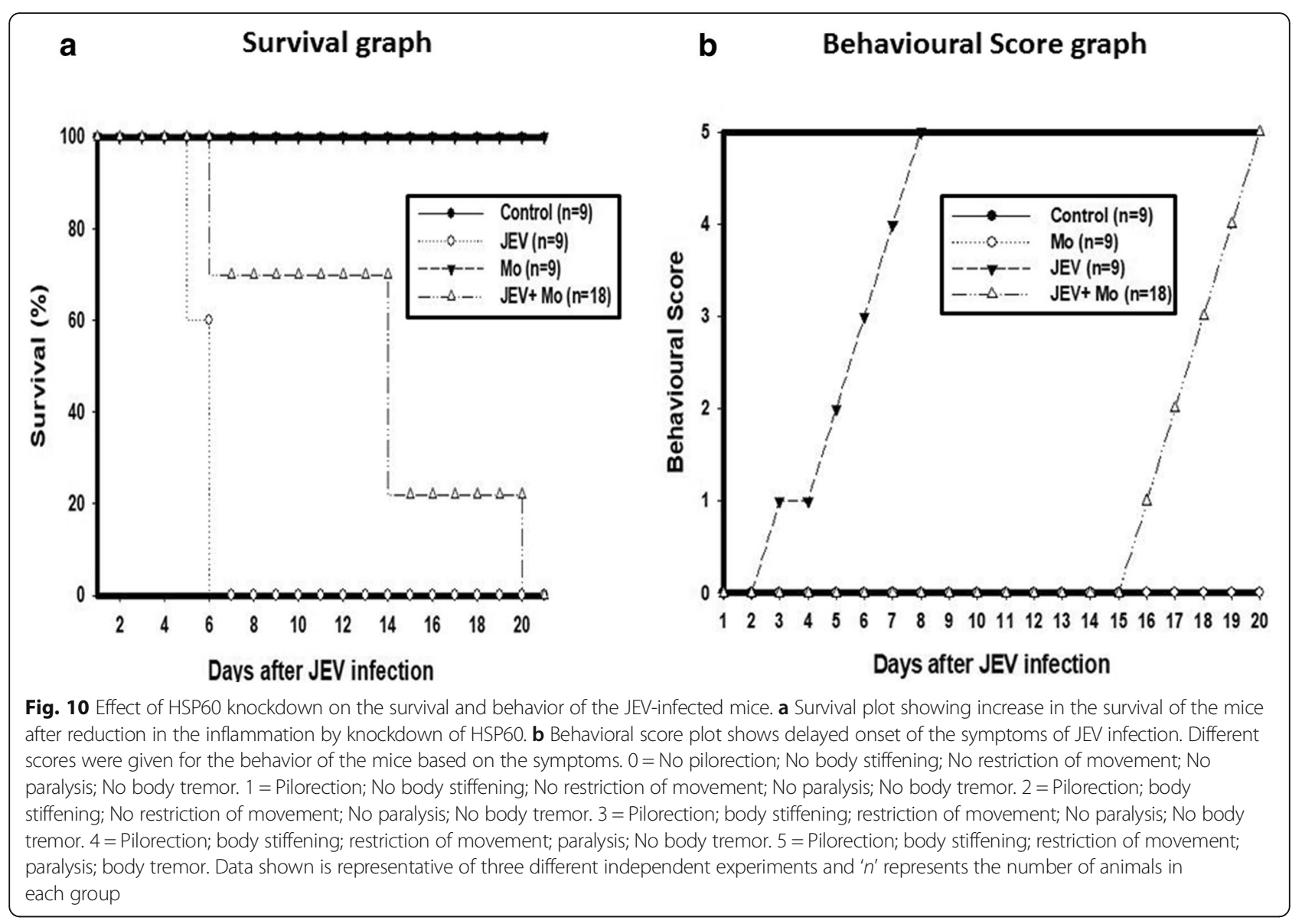

